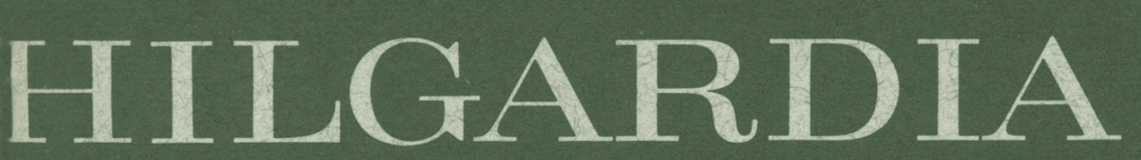

A JOURNAL OF AGRICULTURAL SCIENCE PUBLISHED BY IHE CALIFORNIA AGRICULTURAL EXPER IMENT STATION

Volume 35, Number 6 . November, 1963

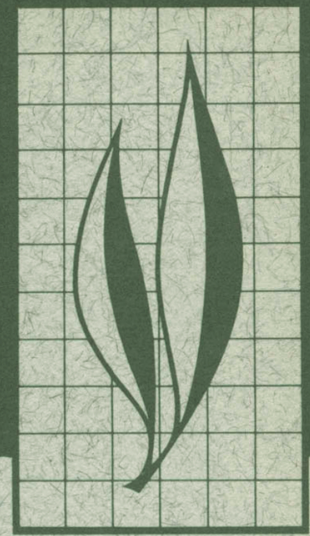

\title{
Causes of Fruit Bruising on Transport Trucks
}

Michael O'Brien, L. L. Claypool, S. J. Leonard, G. K. York, and J. H. MacGillivray 


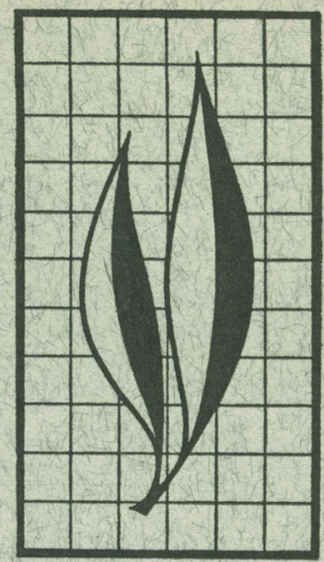

A study of the cause of fruit bruising on transport trucks showed that the damage occurs in the top layers of fruit in containers. The amount of bruising has a direct relation to the magnitude of vibration accelerations in the top levels of fruit. These accelerations, generated at the road surface, are transmitted to the fruit through the truck chassis, suspension system, and bed. The effectiveness of the suspension system determines the extent to which vibration accelerations are minimized before reaching the fruit. Accelera. tions may be as much as four times as great in the top layers as in the bottom layers of fruit. The characteristics of the fruit species and its position in the system determine the acceleration to which it is subjected. Susceptibility to transport bruising varies with type of fruit and variety. In respective order of susceptibility to transport bruising, fruits are (1) cling peaches, (2) round tomatoes, (3) pear-shaped tomatoes, (4) apricots, and (5) pears. Depth-of-bin studies showed an optimum depth of 24 inches; this is related to accelerations in the top layers of fruit and the per cent of total fruit in the bin that is free to move.

\section{THE AUTHORS:}

Michael O'Brien is Lecturer in Agricultural Engineering and Specialist in the Experiment Station, Davis; L. L. Claypool is Professor of Pomology and Pomologist in the Experiment Station, Davis; S. J. Leonard is Food Technologist in the Experiment Station, Davis; G. K. York is Assistant Professor of Food Science and Technology and Assistant Food Technologist in the Experiment Station, Davis; J. H. MacGillivray is Professor of Vegetable Crops and Olericulturist in the Experiment Station, Davis. 
Michael O'Brien, L. L. Claypool,

S. J. Leonard, G. K. York

and J. H. MacGillivray

\section{Causes of Fruit Bruising on Transport Trucks ${ }^{1}$}

\section{INTRODUCTION}

THE EXTENT of bruising of fruit transported on trucks depends upon the frequency, amplitude, and duration of the applied vibration, the amplitude of movement of the container bottom, the height of the container, and the characteristics of the fruit. These amplitudes and frequencies, initiated at the road surface, are minimized to varying degrees by the characteristics of the truck suspension system (Janeway, 1950; Radke, 1958).

Many types of suspension systems are used in the trucks which transport fruit from the field to processing plants, but these systems may be grouped into four main categories: air ride, constant-rate spring, rubber ride, and conventional leaf spring.

Earlier studies (O'Brien et al., 1959) revealed the occurrence of vibration bruising in top layers of eling peaches in lug boxes and bins transported on trucks. When the combination of amplitudes and frequencies in top layers of fruit is sufficient to produce accelerations approaching $1 \mathrm{~g}$ (acceleration of gravity), the top fruits move freely because they receive enough energy from the lower layers of fruit to make them weightless and let them float momentarily (Guillou, Sommer, Mitchell, 1962; Guillou, Mitchell, Richardson, Sommer, 1962; Guillou and Richardson, 1962). As the fruits float freely they receive and transmit successive tangential forces from fruits at the same or lower levels, causing them to rotate.

The fruit cells beneath the skin absorb relatively small impacts that, received for short periods, seemingly do little or no damage, but when impact forces are repeated often enough the cells fatigue and rupture.

Two factors affect the bruising of fruits: the magnitude of force, and number of times this force is repeated at a given location. The interrelations of these two factors are not precisely known (Thompson, 1954). In cling peaches, bruising of unpeeled fruit appears as soft discolored areas below the skin surface. Discoloration is due to oxidation of polyphenol compounds when cell walls are broken. When bruising is severe, the major portion of the fruit surface may be soft and discolored. Only a few fruits of the top layer will show symptoms when bruising is mild, but with severe bruising, damage will extend to nearly all fruits of the top layer, some in the second layer, and to a few in the third layer.

Uncontrolled variables prevent consistent reproduction of bruising effects on test lots of fruit on trucks, but truck vibration information can now be recorded on magnetic tape so that actual conditions can be reproduced by a sophisticated electromagnetic vibrator (Stefanides, 1961). This is expensive, however, so a more realistic approach

${ }^{1}$ Submitted for publication April 17, 1963.

${ }^{2}$ See "Literature Cited" for citations referred to in the text by author and date. 
is to measure the range of vibration amplitudes and frequencies on trucks hauling fruit, and then to subject test lots of fruit to treatment within the ranges measured. It is not necessary to duplicate the complete range of vibration amplitudes and frequencies of trucks, but to obtain precise results it is necessary to duplicate the bruising produced in transit.

\section{MATERIALS AND METHODS}

Transport vibration measurement. amplifiers. A calibrator was devised for Conditions on the four types of trucks mentioned were determined by placing portable recording equipment on the trucks during regular trips from field to canneries (figure 1). The equipment consisted of accelerometer pickups, with cathode followers and cathode-follower amplifiers, a multichannel visicorder chart recorder, and a timer. Power was supplied by a portable A.C. generator. Because slight variations in generated current resulted in drift, a 6 -volt battery with an inverter was used as a power source for the cathode-follower adjustment of the recording amplifiers so that accelerations could be recorded and read directly from the chart in g's. Measurements were made of accelerations in the bottom, middle, and top layers of fruit in bins and in the middle of the bottom, third, and fourth tiers of lug boxes. To achieve direct comparison of vibrating accelerations of different trucks driven at the same speed, the chart recorder was run at the same selected locations along the route for trucks having different suspension systems.

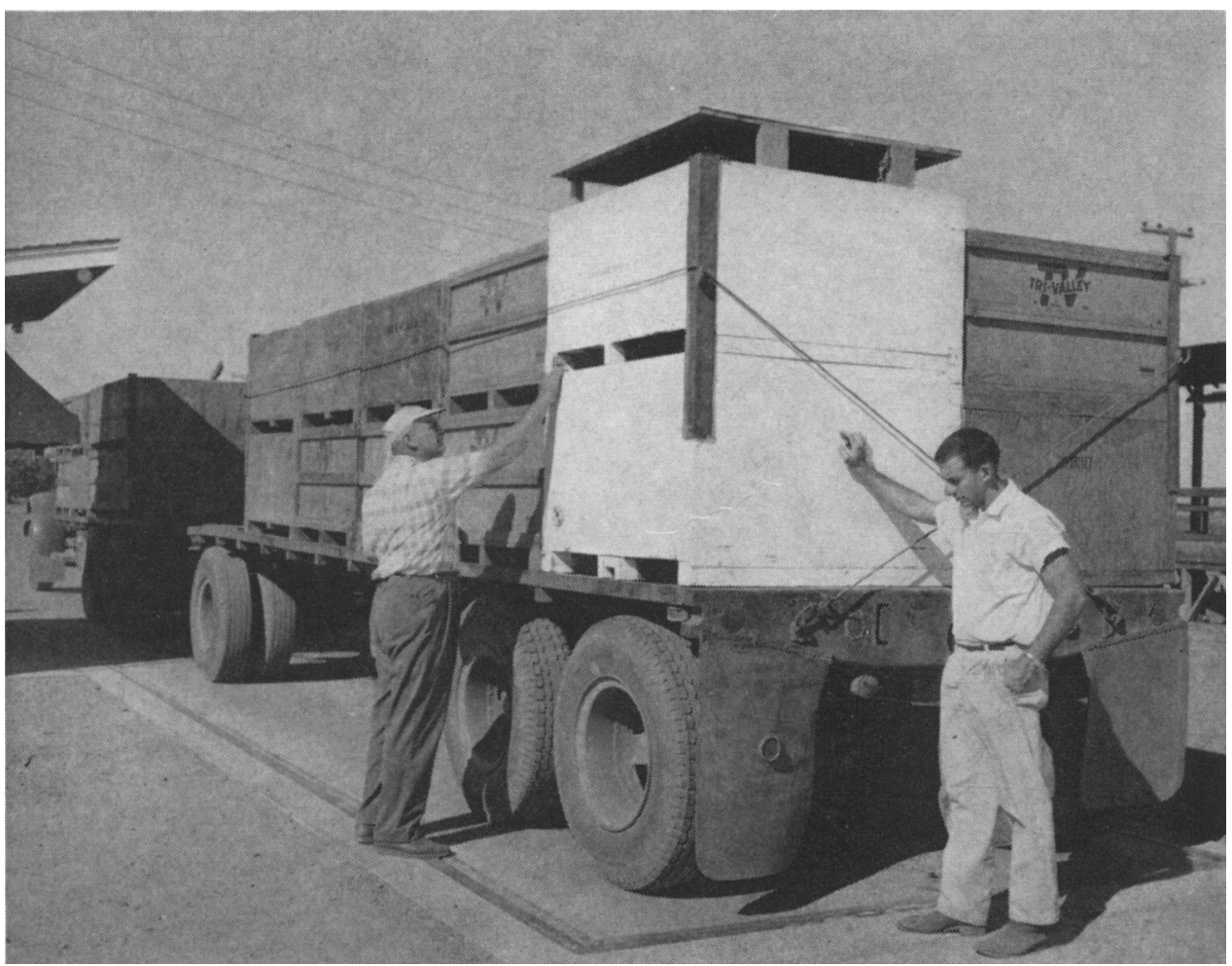

Fig. 1. White bulk bins contain instruments for measuring vibration characteristics of different types of trucks. 
Figure 2 shows average maximum accelerations measured in fruit containers on the trucks. Since the motion of the vibrations is sinusoidal, the expression relating to the three parameters of this graph is $\mathrm{A}=\frac{\mathrm{d}(2 \pi f)^{2}}{386}$, where $A=$ maximum acceleration (in g's), $d=$ single amplitude (inches), and $f=$ frequency, in cycles per second. The loci of these accelerations indicates both the range and the approximate average maximum accelerations for different types of truck suspensions.

Simulated transport equipment. A laboratory vibrator of $1 \frac{1}{4}$-ton capacity powered by an electric motor was constructed to provide amplitudes and frequencies covering the range measured on the trucks. The vibrator table was designed to oscillate on coil springs at the table's natural frequency in order to avoid the large forces and massive construction necessary to provide forced

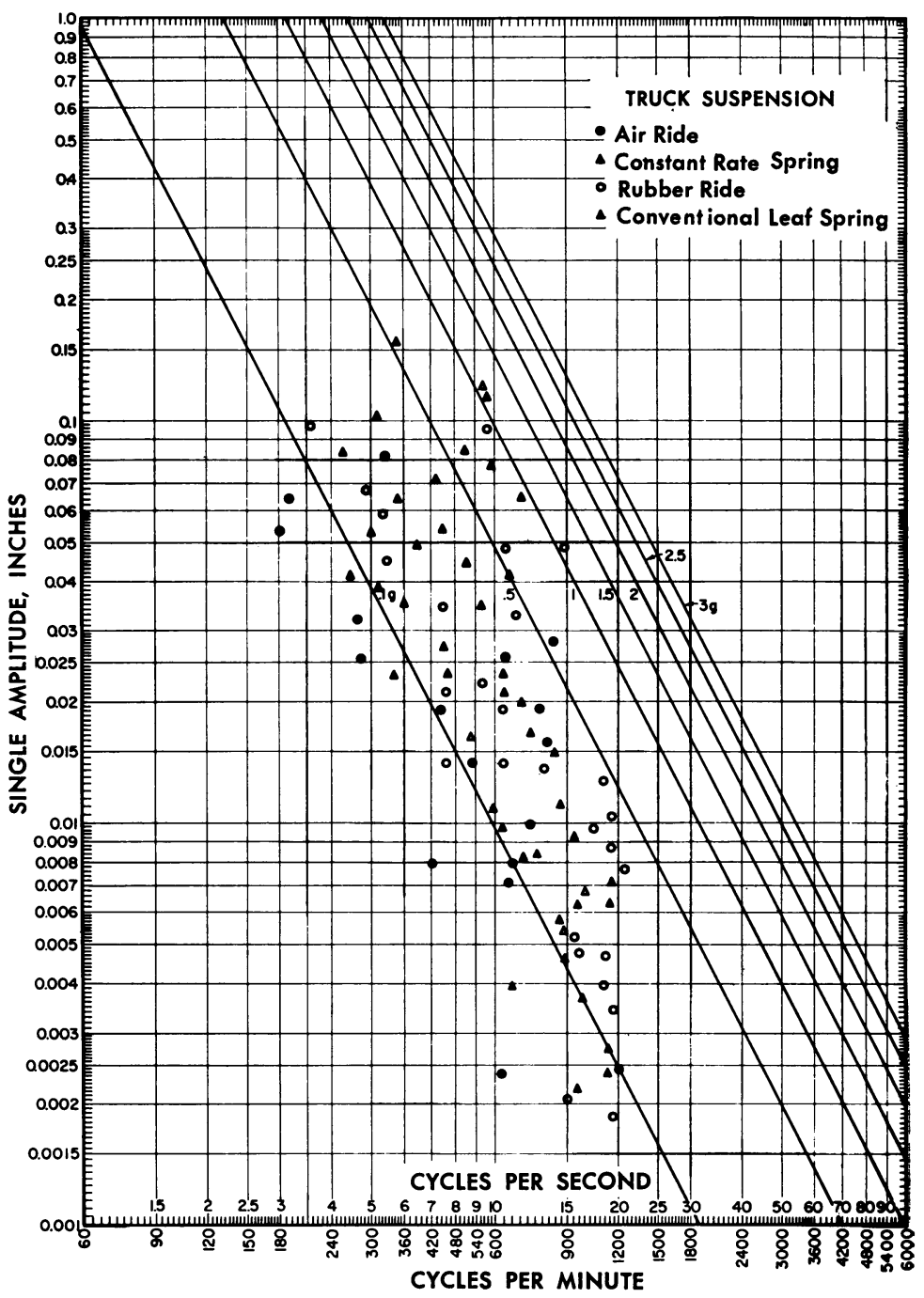

Fig. 2. Measured accelerations of fruit containers on trucks having differing suspension systems. 
vibration. The natural frequency, $f_{n}$, of a spring suspension mass, $m$, is related to the total spring constant, $K$, of the spring suspension by the relations: $f^{n}=\frac{1}{2 \pi} \sqrt{\frac{K}{m}}$.

Undamped forced vibrations were obtained by an actuating system that included adjustable weights on two counter-rotating shafts attached to the table and revolving in opposite directions, providing vertical forces only. The table supporting the counter-rotating shafts was mounted on two cross shafts. The cross shafts were attached to two arms, each pivoted at one end and supported at the movable end by two coil springs. The natural frequency of the table was controlled by adjusting the points of attachment of the two cross shafts along their respective pivoted arms. The natural frequency of the table varic d inversely both with the distance from the axes of the cross shafts supporting the table to the fulcrum, and with the square root of the load on the table.

In comparing the effects of factors such as depth of bin or type of container it is necessary to have equal input accelerations for equal time at the same frequency. Equal input accelerations may be obtained for different loads by increasing the eccentric mass of the driving force.

Test procedures. Tests were conducted with cling peaches, pears, apricots, and tomatoes to determine both the cause of bruising and the susceptibility of these fruits to bruising during transport from the field to processing plants. Containers tested were lug boxes and 1000-pound-capacity bins, 47 inches square and 2 feet deep, with $5 / 8$-inch plywood sides and slotted bottoms of $1 \times 6$-inch boards. Because of the wide

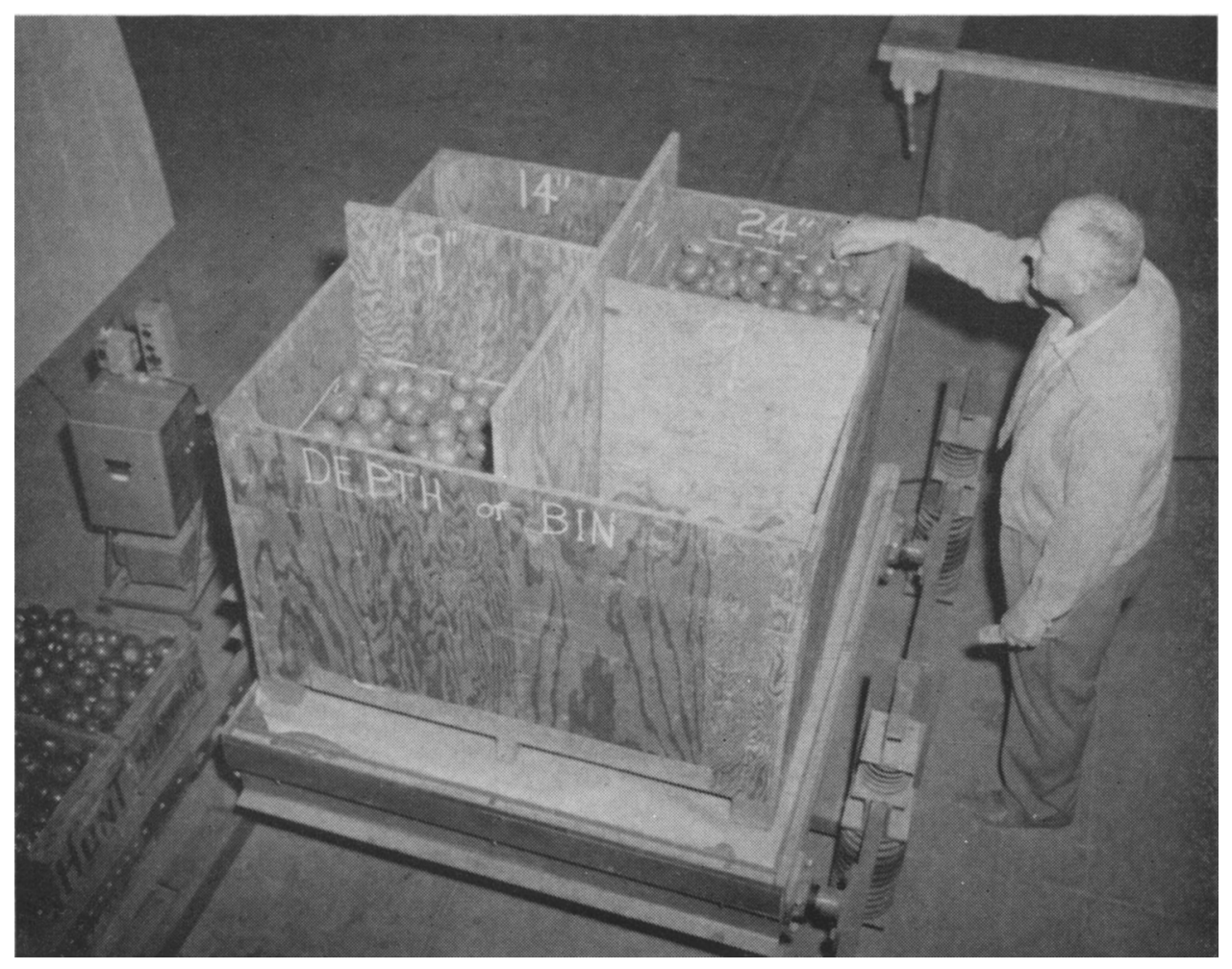

Fig. 3. U.C. 145 tomatoes on simulated-transport vibrator in the laboratory. 
choice of usable bin depths, cling peaches were tested in bins $16,24,32$, 40 and 48 inches deep, and tomatoes in bins $9,14,19$, and 24 inches deep in one series of tests and 12 and 24 inches deep in another (figure 3 ); apricots were tested in lug boxes and in bins 12 , 16, 20, and 24 inches deep. Since transport bruising was negligible in pears delivered to processors, the only comparisons made for pears were between lug boxes and bins 24 inches deep.

Test lots of fruit were picked in the morning and transported with control lots to the laboratory for simulated transit treatment before noon. Each test lot received the simulated treatment about noon and was stored in open air until the next day, when it was evaluated at the pilot plant.

Fruit for simulated transit tests was delivered from the field to the laboratory in such a way as to cause no bruising, using a truck having an air cushion between the regular bed and a secondary bed carrying the fruit. The air cushion was a layer of tires and tubes having air pressure of 2 pounds per square inch. The fruit-hauling bed had a static deflection of $41 / 2$ inches and a natural frequency of 2 cps (cycles per second). Since this "soft" ride caused no damage during delivery to the laboratory, differences found after laboratory vibration were attributed to the simulated transit treatment.

Blenheim (Royal) apricots and three varieties of cling peaches were included in three or more test series of each species. Because air temperatures were excessively high before or during apricot harvest, riper fruits were severely damaged and were culled out during harvest in two of the three series; thus, the remaining fruits were of a maturity more uniform than normal. Cling peaches were harvested to meet the grade requirements of the California Cling Peach Advisory Board. Fruits from three or more pickers were distributed among the bins and lug boxes to minimize any variability between lots that could be attributed to picker differences. Apricots were evaluated the day after treatment by inspecting the fruit from lug boxes and the top, middle, and bottom levels of bins. They were classified as good fruit, slightly bruised, moderately bruised, and severely bruised. Fruit of the first two classifications, when canned, would make choice grade. Fruit of the other two classifications would go into lower grades. Cling peaches were evaluated by peeling all samples whole and sorting into bruised and unbruised categories. The unbruised fruit was weighed and discarded. The bruised fruit was trimmed and further evaluated to determine its useful percentage.

Tomatoes tested were pear-shaped varieties (Red Top and San Marzano), two standard round varieties (VF6 and T2), and VF145, a new round variety developed for mechanical harvesting. (The VF145 variety is somewhat smaller and firmer than standard round varieties.) Fruits from several pickers were included in each of the test lots to minimize the picker variable. Bins were sampled by taking cores of fruit 12 inches in diameter through the full bin depth; lug boxes were evaluated as complete units. The samples were graded into three categories, "good," "soft," and "crushed." Grading was done both at harvest time and 24 hours later, just before canning.

Most Bartlett pears used for processing go from the orchard through the packing houses, where the fruit suitable for fresh packing is removed; the remainder is placed in bins or lug boxes and hauled to canneries, where it is coldstored, ripened, and canned. Pears in these tests were hauled 160 miles on a standard truck to determine if transport bruising was a problem. Evaluation showed no transport bruising that would affect canning quality, and therefore no simulated transit tests were made on pears. 
TABLE 1

VIBRATION CHARACTERISTICS OF TOMATO-HAULING TRUCKS HAVING DIFFERENT SUSPENSION SYSTEMS

\begin{tabular}{|c|c|c|c|}
\hline Suspension system & $\begin{array}{l}\text { Average cycles } \\
\text { per second }\end{array}$ & Acceleration & Displacement \\
\hline & & gravities & inches \\
\hline Air ride. . & 8 & 0.09 & 0.028 \\
\hline Constant rate spring. . & 10 & 0.18 & 0.035 \\
\hline Rubber ride.................. & 11 & 0.19 & 0.031 \\
\hline
\end{tabular}

\section{RESULTS AND CONCLUSIONS}

Vibration measurements on trucks. Truck vibration measurements (table 1) show the average maximum accelerations at the bottom of tomato containers to be respectively $0.09,0.18,0.19$, and $0.20 \mathrm{~g}$ for the air ride, constant-rate spring, rubber ride, and conventional leaf-spring trucks. Measured vibrating frequencies on tomato trucks ranged from 5 to 13 cycles per second, with a mode of 9.9 cycles per second. The upper range of accelerations of tomatoes was $0.3 \mathrm{~g}$ in the bottom layers and seldom exceeded $1.0 \mathrm{~g}$ in the top layers. On trucks hauling cling peaches, the range of vibrating frequencies was from 4 to 18 cycles per second, averaging approximately 13 cycles per second, which was higher than for similar trucks hauling pears, apricots, and tomatoes. The range of acceleration was from 0 to $1.3 \mathrm{~g}$. The differences are thought to be due to differences among the fruits in damping characteristics, but other experiments will be needed to verify this.

In preliminary simulated transit tests, efforts were made to duplicate the bruising conditions found on trucks. Tests showed that bruising observed on trucks after 100 miles of travel could be duplicated by 10 minutes of a $0.25 \mathrm{~g}$ acceleration at a frequency of 10 cycles per second and 0.05 inch of amplitude at the bottom of containers of test lots of cling peaches. This verifies actual observations during truck transit that fruit is often vibrated in the damage range for only short periods. Controlled simulated transport tests were standardized at 10 minutes duration.

Effect of depth of bins. Table 2 shows that the number of bruised peaches per bin was lowest at the 16inch depth and increased with depth to 48 inches. On a percentage basis, however, the per cent bruised fruit was lowest in the 24-inch bin and highest in the 16-inch bin. Fruits in the top layers that are free to move constitute a much higher percentage of total fruit in the 16-inch bin than in the 24-inch bin. The bruise ratio is given numerically in table 2 and shown graphically in figure 4, with the initial and top accelerations in various depth bins.

Tests in 1959 showed the respective ratios of per cent damage in bins 16 , 24,32 , and 40 inches deep to be 1.37 , $1.00,1.17$, and 1.28. Tests were made in 1960 to determine damage in bins 48 inches deep. The bins used were 32 and 48 inches deep in order to key damage in 48-inch bins to previous tests. Test conditions were duplicated. The primary difference was in the fruit. However, since that was the only uncontrolled variable, it was determined that comparisons could be made by keying together results at the 32 -inch depths for the two years. By forcing the values for per cent bruised fruit to coincide for the 32-inch-depth tests made in 1959 and 1960 , the 48-inch comparative value 
TABLE 2

CLING PEACH BRUISING DURING TRANSPORT IN DIFFERENT DEPTH BINS

\begin{tabular}{|c|c|c|c|c|}
\hline Depth of container & $\begin{array}{l}\text { Weight of } \\
\text { fruit tested }\end{array}$ & $\begin{array}{l}\text { Weight of fruit } \\
\text { bruised in test }\end{array}$ & $\begin{array}{l}\text { Per cent of } \\
\text { fruit bruised }\end{array}$ & $\begin{array}{l}\text { Bruised fruit } \\
\text { ratio among } \\
\text { bins }\end{array}$ \\
\hline inches & pounds & pounds & & \\
\hline $16 \ldots \ldots \ldots \ldots \ldots \ldots \ldots \ldots \ldots \ldots \ldots \ldots \ldots \ldots \ldots$ & 667 & 94.0 & 14.1 & 1.37 \\
\hline $24 \ldots \ldots \ldots \ldots \ldots \ldots \ldots \ldots \ldots \ldots \ldots \ldots \ldots \ldots \ldots$ & 1,000 & 103.0 & 10.3 & 1.00 \\
\hline 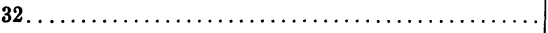 & 1,333 & 161.3 & 12.1 & 1.17 \\
\hline $40 \ldots \ldots \ldots \ldots \ldots \ldots \ldots \ldots \ldots \ldots \ldots \ldots \ldots$ & 1,667 & 220.0 & 13.2 & 1.28 \\
\hline $48 \ldots \ldots \ldots \ldots \ldots \ldots \ldots \ldots \ldots \ldots \ldots \ldots \ldots \ldots \ldots \ldots \ldots$ & 2,000 & 272.0 & 13.6 & 1.32 \\
\hline
\end{tabular}

becomes 1.32. This follows a logical pattern, as the 48-inch bin has slightly more damage than the 40 -inch bin because of greater acceleration in the top layers.

Input accelerations at the bottom of the bins were held constant at $0.25 \mathrm{~g}$, and accelerations in the top layer of fruit varied with the depth of the bins. Figure 4 shows that accelerations were lowest $(0.76 \mathrm{~g})$ in the 16 -inch bins and highest $(1.28 \mathrm{~g})$ in 32 -inch bins.

To find the reason for the nonlinear variation of acceleration in bin depths of 16 to 48 inches, a test was conducted to ascertain the natural frequency of vibration of peaches at a depth of 32 inches. To facilitate the test, compression measurements were conducted to determine the elasticity of peaches. With peaches averaging 2.8 inches in diameter, a force of approximately 15 pounds caused an initial deformation of 0.13 inch but permitted return to the original dimensions when the force was removed. The elasticity was calculated to be approximately 290 pounds per square inch. The following equation describes the vibration of elastic bodies with a node at one end: $f_{n}=\frac{1}{4 \lambda} \sqrt{\frac{E g}{\rho}}$ in which $f_{n}=$ natural frequency, $\boldsymbol{E}=$ elasticity in pounds per square inch, $g=386$ inches per second squared, $\rho=$ density, and $\lambda=$ depth of column of fruit. Although the natural frequency of peaches was 17 cycles per second, damping from hysteresis and friction resulted in maximum vibration at a lower frequency. When the approximate damped natural frequency of the peaches in the 32-inch bin was compared with the forcing frequency of the transport simulator, the fruit was found to be vibrating at closer to resonance in the 32-inch-deep bin than in the bins of other depths, thereby producing high amplitudes of vibration in the top layers of fruit. This is one explanation for the variation among bins in the acceleration of fruit.

Analysis of apricots in bins and lug boxes. Movement of apricots was slight except under severe transport conditions. Two seasons of study indicate that apricots were bruised slightly more in lug boxes than in bins 24 inches deep, and that 24-inch bins had more bruised fruit than bins 12,16 , or 20 inches deep. Figure 5 shows the results of transport

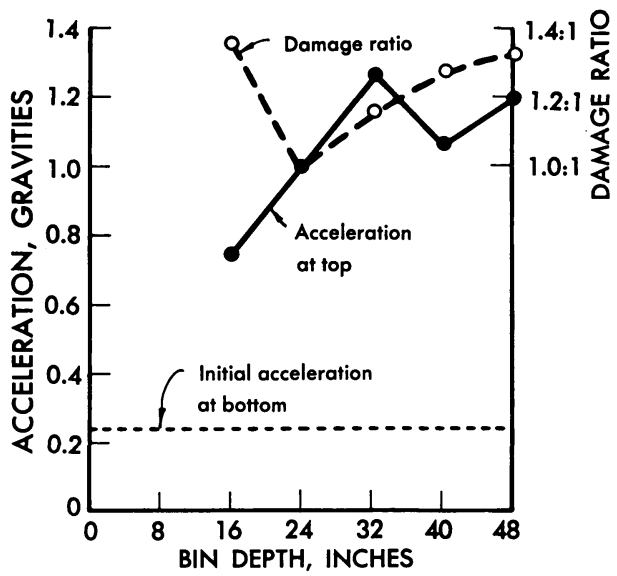

Fig. 4. Acceleration of fruit at the bottom and top of bins receiving simulated transport treatment is related to fruit bruising in bins of various depths. 


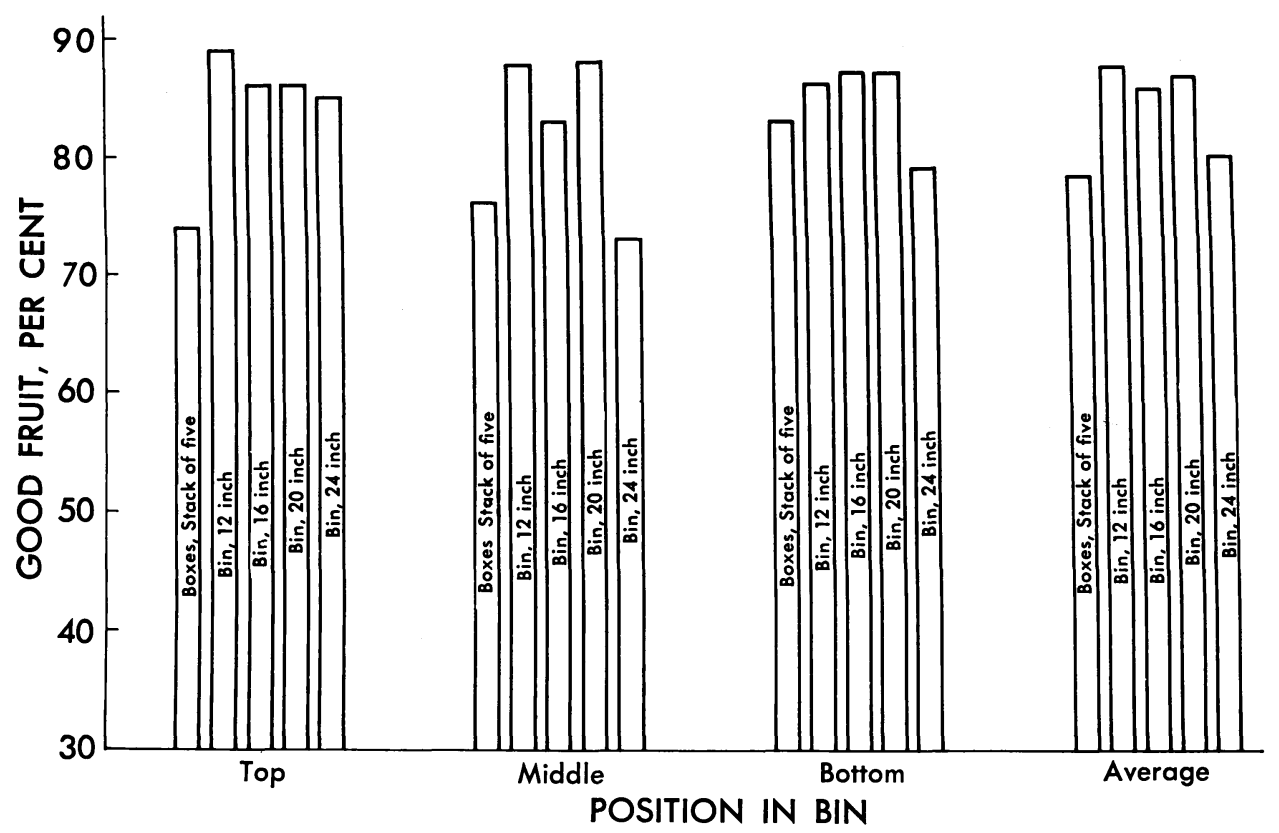

Fig. 5. Summary of transportation studies of Blenheim (Royal) apricots in bulk bins and lug boxes.

studies with Blenheim (Royal) apricots in lug boxes and bins of different depths. Fruit in the bottom and middle layers was bruised more in the 24-inch bin than in any other container, and at all levels fruit bruising was uniformly less in bins 12, 16, and 20 inches deep than in lug boxes or bins 24 inches deep.

The variation of acceleration with bin depth was not as pronounced for apricots as for peaches. Elasticity is approximately one-fourth as much for apricots as for peaches, with the natural frequency consequently ranging from 0.37 to 0.75 cps as bin depth increases from 12 to 24 inches, a range of frequencies far below the forced frequency of $10 \mathrm{cps}$ used for the tests. These low frequencies explain why damaging fruit movement of apricots occurs only under severe vibration not normal in transport. Most transport injury of apricots results from compression of the more mature fruit.

Effects of transport on tomatoes. Table 3 shows that approximately 11 per cent of the fruit in the 12 -inch bins was reduced from the good to the soft grade by simulated transit treatment and storage for 24 hours. The amount of crushed and cull fruit did not change. In the 24-inch bin, approximately 9 per cent of the fruit moved from the good to the soft grade during transport and storage.

Damage to pear-shaped tomatoes in simulated transit and storage was slight. Table 4 shows very little difference in fruit damage between lug boxes and bins 9-24 inches deep, although the 24-inch bin did have slightly more soft fruit than did other bins or lug boxes.

The standard round varieties, VF6 and $\mathrm{T} 2$, suffered considerable damage during simulated transit treatment and storage. Table 4 shows no consistent pattern of differences among the containers.

Relation of bruising to position in container and to accelerations. Table 5 shows fruit bruising in bins of peaches receiving high input accelerations of $0.36 \mathrm{~g}$; table 6 shows bruising in lug boxes of peaches receiving input 
TABLE 3

CONDITION OF VF145 TOMATOES AFTER SIMULATED TRANSPORT TREATMENT AND STORAGE IN BINS OF TWO DEPTHS

\begin{tabular}{|c|c|c|c|c|c|c|c|c|c|}
\hline \multirow{3}{*}{ Time of test } & \multirow{3}{*}{$\begin{array}{l}\text { Num- } \\
\text { ber of } \\
\text { tests }\end{array}$} & \multicolumn{8}{|c|}{ Condition of tomatoes } \\
\hline & & \multicolumn{4}{|c|}{ 12-inch bins } & \multicolumn{4}{|c|}{ 24-inch bins } \\
\hline & & Good & Soft & Crushed & Culls & Good & Soft & Crushed & Culls \\
\hline & & per cent & per cent & per cent & per cent & per cent & per cent & per cent & per cent \\
\hline At harvest. & 3 & 80.1 & 6.0 & 9.3 & 3.7 & 80.2 & 3.6 & 13.8 & 2.4 \\
\hline At canning $\ldots \ldots \ldots \ldots \ldots$ & 3 & 69.2 & 18.9 & 8.9 & 3.0 & 71.2 & 14.8 & 10.5 & 3.5 \\
\hline
\end{tabular}

accelerations of $0.34 \mathrm{~g}$. Under these severe transport conditions, 15 per cent of the fruit is bruised in lug boxes, and 10 per cent in bins.

This higher bruising in lug boxes can be attributed to the fact that the progressively higher acceleration in fruit from bottom to top is greater in stacks of boxes than in bins. Figure 6 shows less difference in accelerations between bottom and top than is shown in tables 5 and 6 ; the primary difference is that figure 6 was recorded in tomato tests, and tables 5 and 6 in tests with cling peaches. Figure 6 shows the higher accelerations of tomatoes in lug boxes in successively higher tiers; accelerations were about twice as great in the third tier as in the bottom tier, and about $2 \frac{1}{2}$ times as great in the fifth tier. Further, the initial accelerations in figure 6 are over $0.4 \mathrm{~g}$, making these magnifications more important than with lower accelerations.

In figures 6 and 7 the vibration accelerations of tomatoes in lug boxes stacked five high are compared with 2foot-deep bins. Bins and boxes were vibrated at the same time on the same transport vibration simulator, and the recordings made simultaneously. The lower accelerations in the bottom of the bin (as compared to the bottom tier of boxes) are due in part to the placement of the vibration pickup. The placement of the pickup was intentional, because accelerations vary from bottom to top in the lug boxes, and an average value was desired. The average was approximated by fruit in the bottom layer of the bin and by the second and third layers of fruit in the bottom tier of lug boxes. However, accelerations were somewhat lower in the middle part of

TABLE 4

\section{CONDITION OF TOMATOES AFTER SIMULATED TRANSPORT TREATMENT IN CONTAINERS OF DIFFERENT DEPTHS}

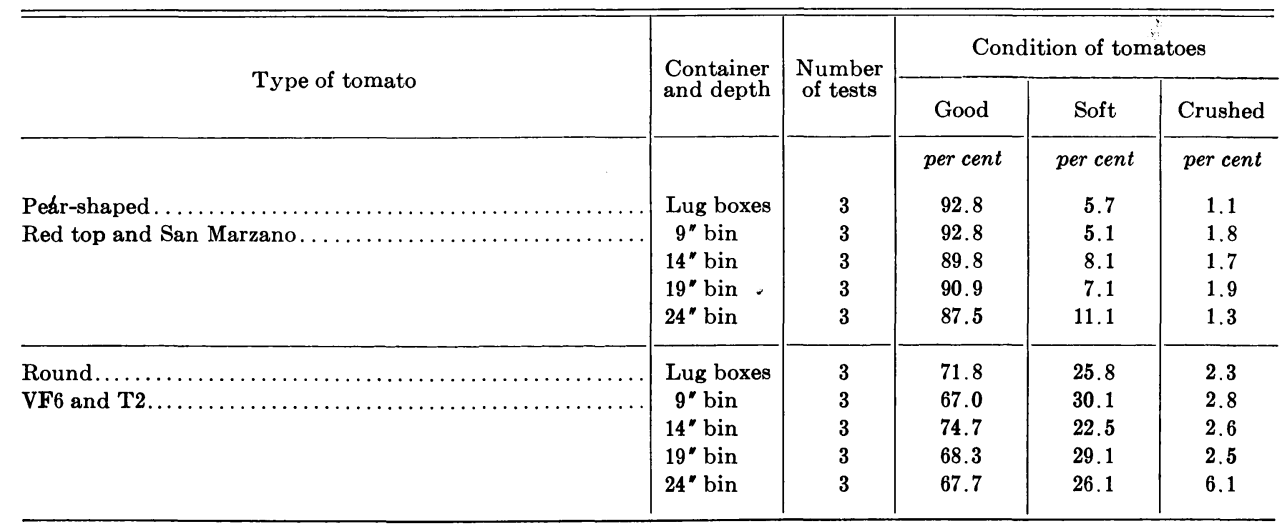




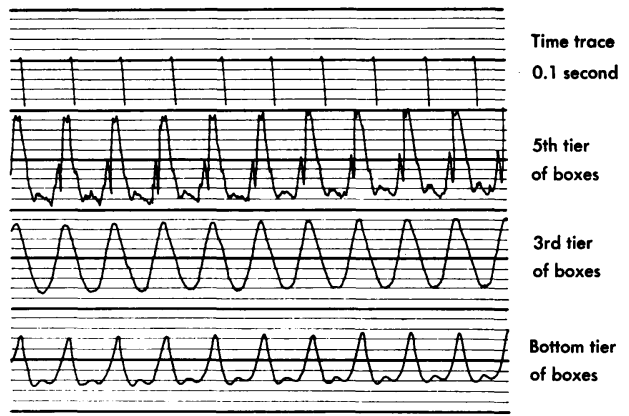

Fig. 6. Vibration accelerations of tomatoes in various tiers in a stack of lug boxes during simulated transport treatment in the laboratory. (One $\mathrm{g}$ equals a double amplitude of 10 divisions on the chart.)

the bin than in the bottom lug box. One reason for the discrepancy is that fruit in the middle of the bin is restrained by the layers of fruit above, whereas fruit in lug boxes is in only 3 layers and

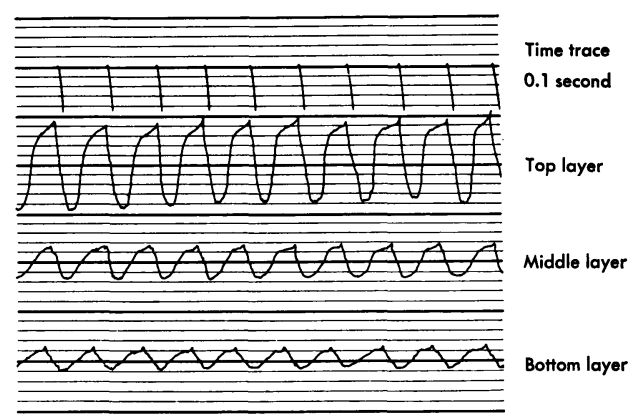

Fig. 7. Vibration accelerations of tomatoes in various levels in bins during simulated transport treatment in the laboratory. (One g equals a double amplitude of 10 divisions on the chart.)

therefore is more readily movable. Figure 8 shows the placement of vibration pickup in a lug box of peaches.

Figures 6 and 7 show that the lag in peak accelerations at successively higher

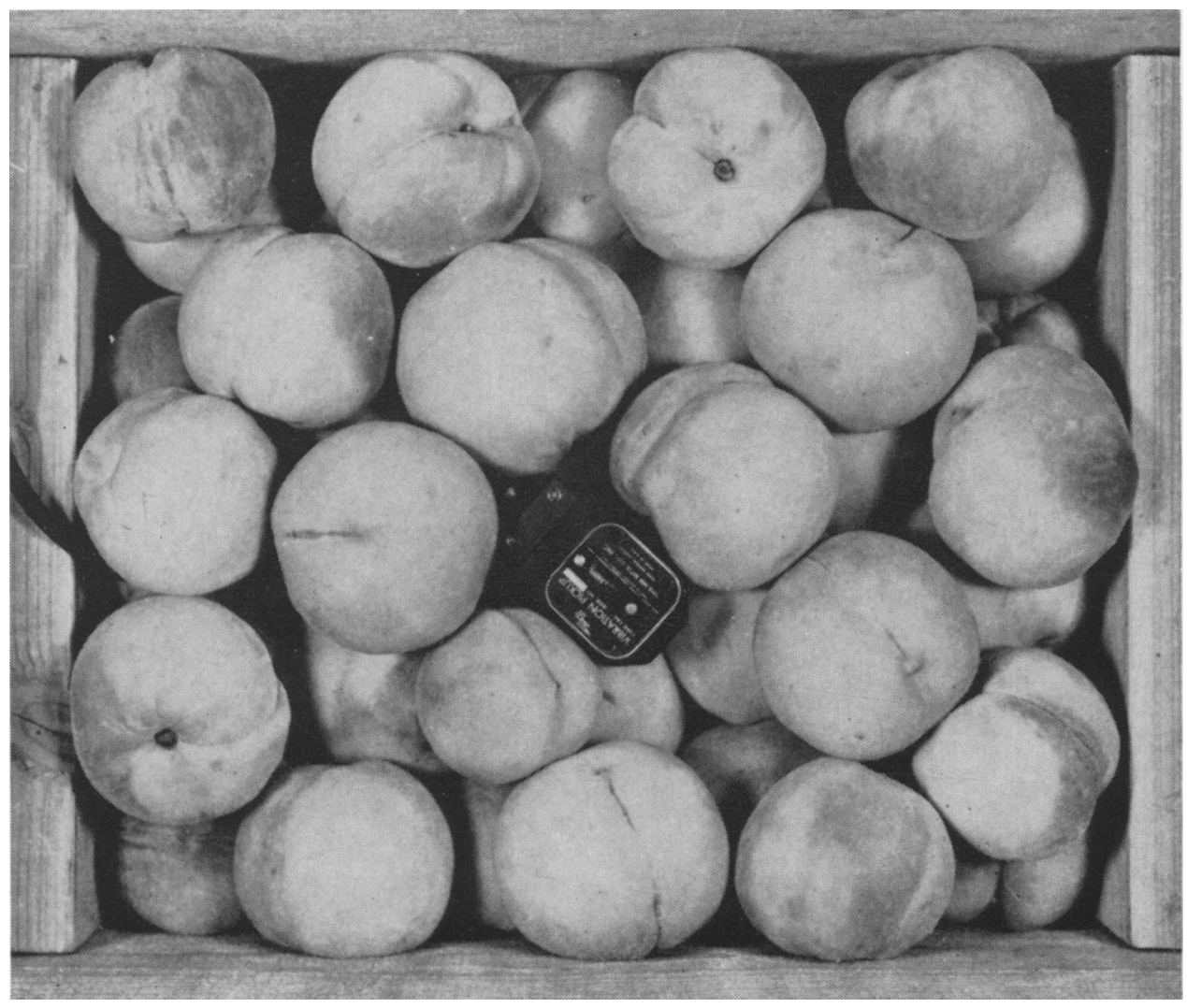

Fig. 8. A vibration pickup positioned in a lug box of peaches. 


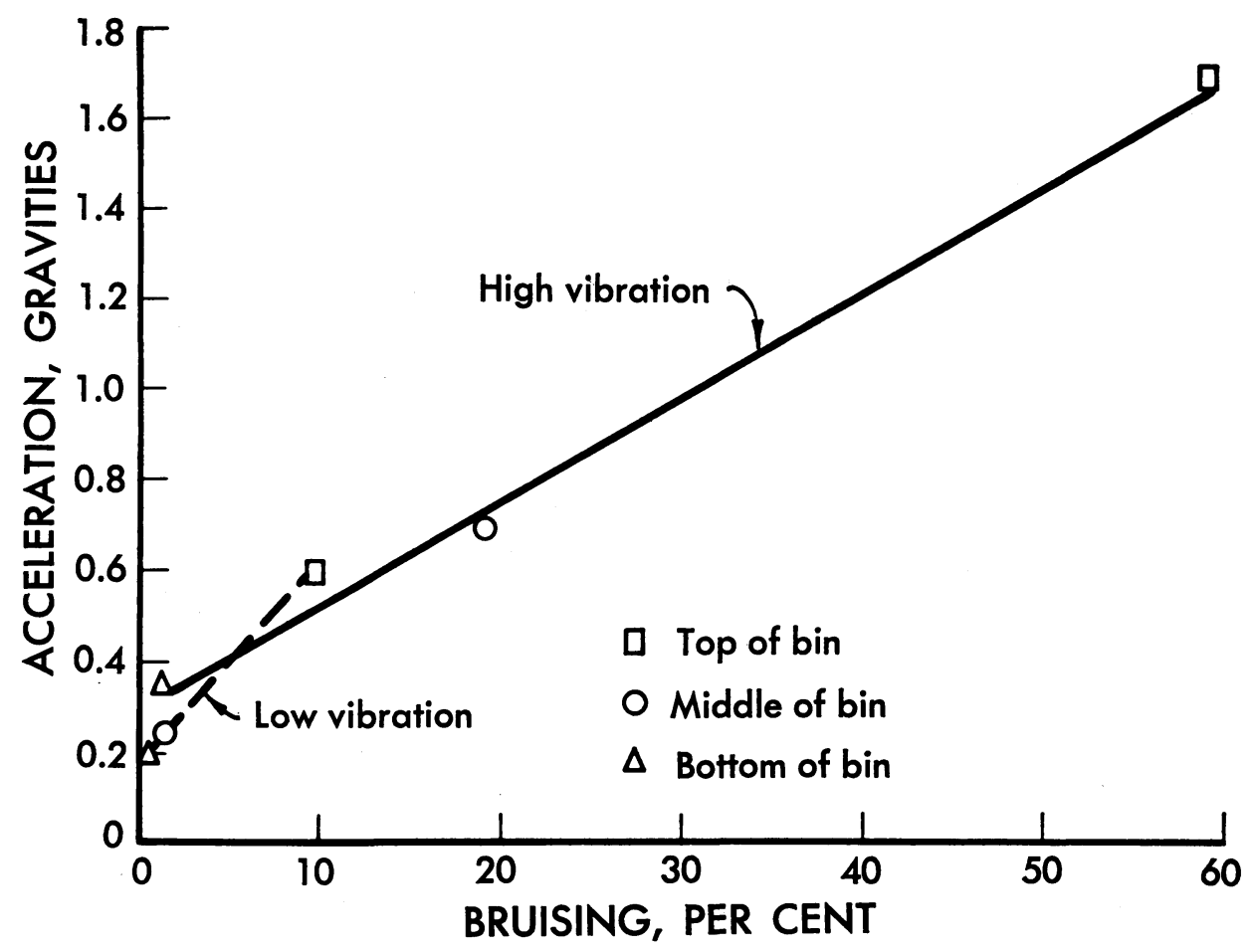

Fig. 9. Comparison of fruit in bins receiving high or low vibrating accelerations for equivalent of a 100-mile ride. Fruit damage results primarily from high accelerations.

levels was greater in bins than in higher tiers of lug boxes. Peak accelerations are approximately one-third of a cycle later at the top of the bins than at the bottom, and almost simultaneous in boxes; this is because vibrations are transmitted through wood to successive tiers of lug boxes in one case and through fruit in bins in the other. Hysteresis of the fruit causes the vibration lag from the bottom to the top fruit in bins.

In any type of container the fruit can float freely when it receives enough energy to overcome the forces of gravity and inertia; this phenomenon exists when acceleration exceeds $0.75 \mathrm{~g}$. Since vibration forces are always highest in the top layer of fruit, it is the top layers that receive the most bruising from high accelerations. Individual lug boxes have a much higher per cent of their fruit in top layers than do bins, and conse- quently are more vulnerable to vibration bruising.

Significance of severity of accelerations. When fruit is subjected to severe vibrations with accelerations exceeding $1.0 \mathrm{~g}$ in the top layers, the second and even third layers of fruit from the top can have enough movement to be damaged. Figure 9 shows the amount of

TABle 5

BRUISING AND ACCELERATIONS OF CLING PEACHES AT VARIOUS LEVELS IN STANDARD 24-INCH-DEEP BINS RECEIVING SEVERE TRANSPORT TREATMENT

\begin{tabular}{c|c|c}
\hline Levels & Bruised fruit & Accelerations \\
\cline { 2 - 3 } & per cent & gravities \\
Top $1 / 3 \ldots \ldots \ldots \ldots \ldots \ldots \ldots \ldots \ldots \ldots \ldots$ & 23.9 & 1.04 \\
Middle $1 / 3 \ldots \ldots \ldots \ldots \ldots \ldots$ & 4.8 & 0.58 \\
Bottom $1 / 3 \ldots \ldots \ldots \ldots \ldots$ & 1.6 & $0.36^{*}$ \\
\hline
\end{tabular}

* Input accelerations at bottom. 
Table 6

BRUISING AND ACCELERATIONS OF CLING PEACHES AT VARIOUS LEVELS IN STACKS OF LUG BOXES RECEIVING SIMULATED TRANSPORT TREATMENT

\begin{tabular}{|c|c|c|}
\hline Levels & Bruised fruit & Accelerations \\
\hline & per cent & gravities \\
\hline 5th tier $\ldots \ldots \ldots \ldots \ldots \ldots$ & 18.8 & 1.22 \\
\hline 3rd tier............... & 16.8 & 0.64 \\
\hline Bottom tier........ & 12.6 & $0.34^{*}$ \\
\hline
\end{tabular}

* Input accelerations at bottom.

bruising that results from high or low vibration accelerations for the same period. After a simulated 100-mile ride, bins receiving accelerations of $0.2 \mathrm{~g}$ at the bottom had a total of 4 per cent bruised fruit, in contrast to 25 per cent bruised fruit in bins receiving $0.35 \mathrm{~g}$.

Figure 10 compares the fruit bruising that results from severe simulated transport treatment. The per cent of totally bruised fruit was somewhat greater in boxes than in bins. The per cent of bruised fruit that required trimming was about the same for each, as

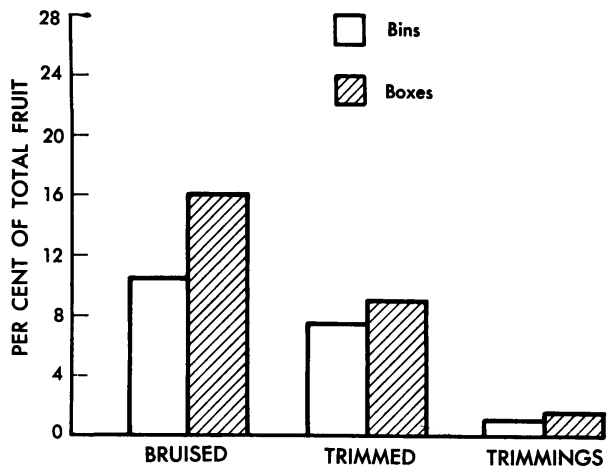

Fig. 10. Analysis of bruised fruit in lug boxes and bins receiving similar simulated severe transport treatment for equivalent of a 100-mile ride. Lug boxes suffered more losses than bins.

was the per cent of trimming waste.

In several tests, sponge padding and crushed ice were used to prevent movement of the top layers of fruit during transit and each eliminated bruising due to vibrations. These tests revealed the significance of preventing movement of the top layers of fruit to reduced bruising of fruit. As a result of this finding some top icing is being done.

\section{LITERATURE CITED}

Guillou, Rene, Noel F. Sommer, and F. Gordon Mitchell.

1962. Simulated transit testing for produce containers. TAPPI 45(1):176A-178A.

Guillou, Rene, F. Gordon Mitchell, H. B. Richardson, and Noel F. Sommer

1962. Tight-fill fruit packing. Univ. of Calif. Mimeo:1-14.

GuILlou, RENE, and H. B. RichaRdson

1962. Grape container testing in simulated transit laboratory. Calif. Agr. 16(7):14-15.

JANEWAY, R. N.

1950. Elimination of damaging shock and vibration in freight cars. Shock and Vibration Bul. $15: 66$.

O'Brien, M., L. L. Claypool, and Sherman Leonard

1959. Bulk handling of cling peaches. Univ. of Calif., College of Agriculture Mimeo:1-32.

RADKE, A. O.

1958. Vehicle Vibration, Mechanical Engineering 80(7) :38-41.

STEFANIDES, E. J.

1961. Elastomeric suspension systems for shipping containers. Design News 16(20):4-5.

Thompson, W. T.

1954. "Mechanical Vibrations." Prentice Hall, Inc., New York, New York. 
The journal HILGARDIA is published at irregular intervals, in volumes of about 650 to 700 pages. The number of issues per volume varies.

Single copies of any issue may be obtained free, as long as the supply lasts; please request by volume and issue number from:

\section{Agricultural Publications \\ University Hall \\ University of California \\ Berkeley 4, California}

The limit to nonresidents of California is 10 separate titles. The limit to California residents is $\mathbf{2 0}$ separate titles.

The journal will be sent regularly to libraries, schools, or institutions in one of the following ways:

1. In exchange for similar published material on research.

2. As a gift to qualified repository libraries only.

3. On a subscription basis $-\$ 7.50$ a year paid in advance. All subscriptions will be started with the first number issued during a calendar year. Subscribers starting during any given year will be sent back numbers to the first of that year and will be billed for the ensuing year the following January. Make checks or money orders payable to The Regents of The University of California; send payment with order to Agricultural Publications at above address. 